\title{
Surface Plasmon Resonance Biochips for Tuberculosis Bacillus Detection
}

\author{
Jhen-Gang Huang ${ }^{1}$, Chi-Chan K. Hung ${ }^{1}$, Hsin-Chih Lai ${ }^{3}$,Chih-Kung Lee ${ }^{4}$, Shi-Ming Lin ${ }^{5}$, \\ Ping Feng ${ }^{6}$, Chii-Wann Lin ${ }^{1,2^{*}}$ \\ Institute of Biomedical Engineering ${ }^{1}$, Department of Electrical Engineering ${ }^{2}$, Department of Medical \\ Technology $^{3}$, Institute of Applied Mechanics ${ }^{4}$, Center of Optoelectronic Biomedicine ${ }^{5}$, \\ National Taiwan University, Taipei, Taiwan, R.O.C., Kuang Wu Institute of Technology ${ }^{6}$
}

\begin{abstract}
Tuberculosis is one of notifiable infectious diseases which may cause serious epidemic problems. Traditional diagnostic techniques include acid- fast stain, bacteria culture, metabolic monitoring have some disadvantages such as low sensitivity, time consumption and less specificity. In this study we proposed a new diagnostic technique based on the protein chips concept which detected by SPR phenomena. It was found that the resonance angle $\left(\sim 51.86^{\circ}\right)$ shifted slightly toward right with antibody concentration of $10 \mathrm{X}, 30 \mathrm{X}, 100 \mathrm{X}$, and $300 \mathrm{X}$ dilution under optimal concentration of immobilized TB antigen W38 (MW 41.5 kDa, $50 \mu \mathrm{g} / \mathrm{ml}$ ). While for the W06 (MW $14 \mathrm{kDa}, 50 \mu \mathrm{g} / \mathrm{ml}$ ), the resonance angle was around $50.13^{\circ}$ and shifted with the same trend as W38 did.
\end{abstract}

Keyword: protein chip, SPR, Tuberculosis bacillus

\section{INTRODUCTION}

Tuberculosis is one of notifiable infectious diseases, which is caused by the invasion of Mycobacterium tuberculosis. According to the estimation of WHO [1], there were 2 million people die result from this disease in 2002. Traditional diagnostic techniques include acid- fast stain, bacteria culture, metabolic monitoring and nucleic acid diagnosis. However these techniques are not suitable for mass screening for some disadvantages: acid-fast stain is less sensitive $\left(10^{5}\right.$ bacteria/ $\left.\mathrm{ml}\right)$, bacteria culture need 30 day bacteria culture, metabolic monitoring is less specificity and nucleic acid diagnosis is too expensive.

Using proteins as detection probes has some advantages such as specimen is easy to obtain [2]. However, the complexity of protein conformation caused the accuracy was difficult to confirm. In this study we proposed a new diagnostic technique based on the protein chips concept which detected by SPR phenomena. TB antigen with different species specific sequences was immobilized onto different array sites. Then specimen with TB antibodies was added to interaction with antigens on the chips. Finally, the interaction of antibodies interacted was monitored by SPR imager.

\section{Materials And MethodS}

1) Reagent: All reagents were prepared with deionic water. The thiol linker with 8 alkyl backbone and carboxyl function group was synthesized in laboratory. 1-ethyl-3- (3-dimethylaminopropyl) carbodimide (EDC) and N-hydroxysuccinimide (NHS) was purchased from Acros. Phosphate buffer solution (PBS) was prepared with $1.36 \mathrm{M}$ $\mathrm{NaCl}, 26.8 \mathrm{mM} \mathrm{KCl}, 50 \mathrm{mM} \mathrm{Na} \mathrm{HPO}_{4}$ and $17.6 \mathrm{mM}$ $\mathrm{KH}_{2} \mathrm{PO}_{4}$ and adjusted $\mathrm{pH}$ to 7.4. All biological samples were prepared with PBS.

2) Microchip fabrication: The glass substrates for gold film fabrication were first cleaned by piranha solution $\left(\mathrm{H}_{2} \mathrm{SO}_{4}: \mathrm{H}_{2} \mathrm{O}_{2}=3: 1\right)$ at $80^{\circ} \mathrm{C}$ for $5 \mathrm{~min}$ and $\mathrm{H}_{2} \mathrm{O}_{2}: \mathrm{NH}_{4} \mathrm{OH}$ : $\mathrm{H}_{2} \mathrm{O}=0.2$ : $1: 5$ at $85{ }^{\circ} \mathrm{C}$ for $30 \mathrm{~min}$ subsequently. Then positive photoresist Shipley S1813 (Microposit co.) was spin coated on glass substrate for array patterning and was softbaked at $90^{\circ} \mathrm{C}$ for $45 \mathrm{sec}$. After the lithography and development step, negative image of array pattern was transferred onto the photoresist film, and then $1 \mathrm{~nm} / 50 \mathrm{~nm}$ $\mathrm{Cr} / \mathrm{Au}$ film was then deposited onto the patterned photoresist on the glass substrates by E- beam evaporator. Finally, unwanted photoresist was removed by acetone and then undesired part of metal layer was lifted off from biochips. The diameter of each gold reaction site was two $\mathrm{mm}$, as shown in Fig. 1.

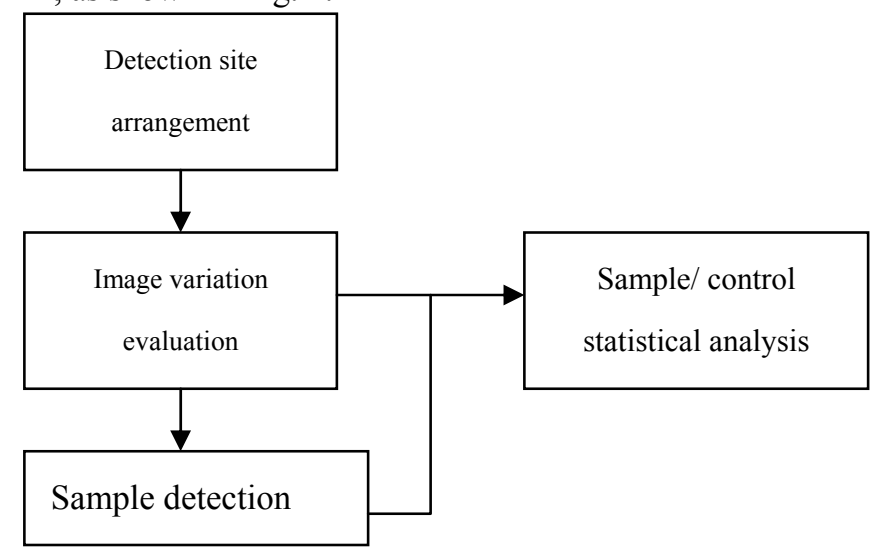

Fig.1 Illustration of accuracy evaluation by imaging processes.

3) Biomolecular immobilization [3-4]: The linker was first poured onto glass biochips with gold-film array for $20 \mathrm{~min}$. After the self-assembly monolayer of linker was formed on the gold surface, $400 \mathrm{mM}$ EDC and $100 \mathrm{mM}$ NHS was added onto the gold film area to activate the carboxyl group. Here, four different concentration of TB antigen W38 and 
W14 individually were applied to seek for the optimal interaction of antibody-antigen, i.e. $5 \mu \mathrm{g} / \mathrm{ml}, 10 \mu \mathrm{g} / \mathrm{ml}, 20$ $\mu \mathrm{g} / \mathrm{ml}$ and $50 \mu \mathrm{g} / \mathrm{ml}$. After the TB antigen was added, the antigen molecules were anchored on the linker covalently. To avoid the unspecific binding on the unbounded linker, 1 $\mathrm{M}$ ethanolamine was added to block the unbounded linker sites after antigen were immobilized.

4) SPR detection on biochips: The SPR signal detection was accomplished by GWC SPR imager (GWC Technologies Inc. Madison, USA). As the molecular interaction happened on the surface, SPR resonance angle is influenced, which could be monitored by the alternation of image intensity at resonance angle or changes in resonance angle [5]. To avoid environment noise interfered data analysis, the SPR curve was normalized before plot and analysis.

5) Data analysis: In order to ensure the accuracy of antibody-antigen interactions on detection site, image intensity was evaluated by a serial process as shown in Fig.1. Detection sites arrangement on biochips was shown in Fig. 2. All eight sites on the same chip were immobilized with the same antigen concentration. To evaluate the intensity variation between experimental set and control set, images from control sites were first analyzed statistically. Then, four different sites of experimental set were analyzed subsequently to verify the accuracy of antibody-antigen interaction on the chip.

\section{RESULTS}

1) Evaluation of the accuracy for chip system: The resonance angle analysis of control set was shown in Fig. 3 and Fig. 5 respectively. It was found that the image intensity standard error between four detection sites of control set from $45^{\circ}$ to $55^{\circ}$ was less than $4.1 \%$ for $\mathrm{W} 38$ and $6 \%$ for W06 when chips were immobilized with $50 \mu \mathrm{g} / \mathrm{ml}$ antigens. It was shown that the SPR signal presented excellent reproducibility, so it could be used to detected antibody- antigen interaction.

2) Detection of antibody-antigen interaction on the biochip: The detection efficiency could be influenced by antigen immobilized concentration, antibody concentration, antibody titer and antigen characteristics. For obtaining optimal immobilization concentration of different antigen, TB antigen W38 with $41.5 \mathrm{kDa}$ molecular weight and W06 with $14 \mathrm{kDa}$ molecular weight were immobilized with four

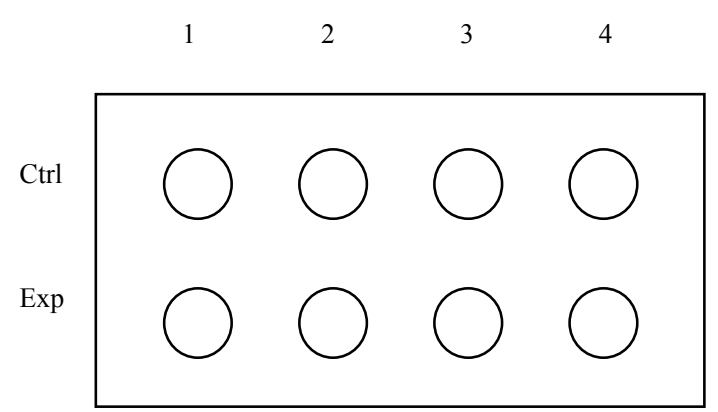

Fig. 2 Detection site arrangement of biochip. C: control, E:

experiment

different concentration of antigen, and interacted with polyclonal antibody at 10X, 30X, 100X and 300X dilution. Eventually, we found that the experimental set of antigen with concentration of $50 \mu \mathrm{g} / \mathrm{ml}$ for W38 could give a more evident variation of resonance angle shift to the control set other than three lower concentration samples. Resonance angle curve with different antibody dilution ratio was shown in Fig. 4. As compared with control set of S.D. value of 0.02 at resonance angle $51.86^{\circ}$, the resonance angle shift slightly toward right with the variation of the concentration of selected antibody when we immobilized antigen with 50 $\mu \mathrm{g} / \mathrm{ml}$, and the statistics of normalized image intensity ranging from $48.5^{\circ}$ to $50.5^{\circ}$ was shown in Table 1 . Besides the antibody with $10 \mathrm{X}$ dilution, the intensity difference between experimental set and control set was more than 3 times of S.D. and image intensity increased with decreased antibody concentration. The statistics of resonance angle was obtained by curve fitting under Lorentz model. Table 2 showed resonance angle shift of experimental set. For $50 \mu \mathrm{g} / \mathrm{ml}$ of W06, the experimental set of antigen showed a more apparent variation of resonance angle shift than three other specimens of different concentration as compared to the control set, as shown in Fig. 6. The statistics of resonance angle shift of experimental set was shown in Table 3. According to the results, we know that antibody-antigen interaction could be evaluated through this proposed system.

\section{DISCUSSION}

In this study, we had proposed a protein chip system for TB detection. For the TB antigen, the optimal concentration for immobilization was $50 \mu \mathrm{g} / \mathrm{ml}$ of $\mathrm{TB}$ antigen W38, and we discovered that the relationship between antibody concentration and image intensity could be obviously observed from $48.5^{\circ}$ to $50.5^{\circ}$ when immobilized antigens interacted with selected antibodies. It showed that protein detection could be accomplished on this chip system. For complete diagnostic chip development, different types of antigens with specific sequences should be prepared on the chip system, so as to verify the accuracy 
of diagnosis. According to this manner, more species specific antigen would be evaluated in the future.

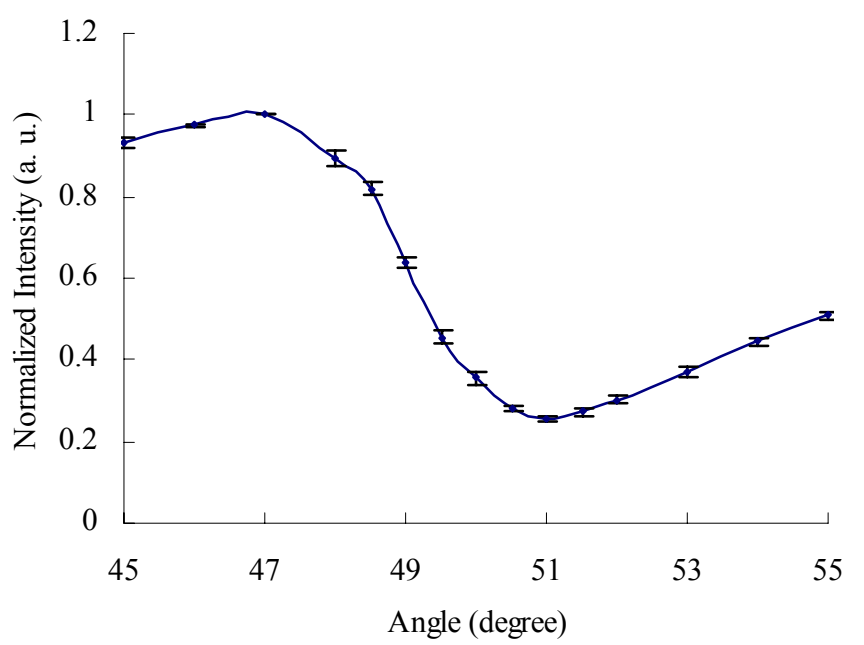

Fig. 3 Resonance angle analysis of control experiment $(\mathrm{n}=4$ for each data points) $\mathrm{W} 38$

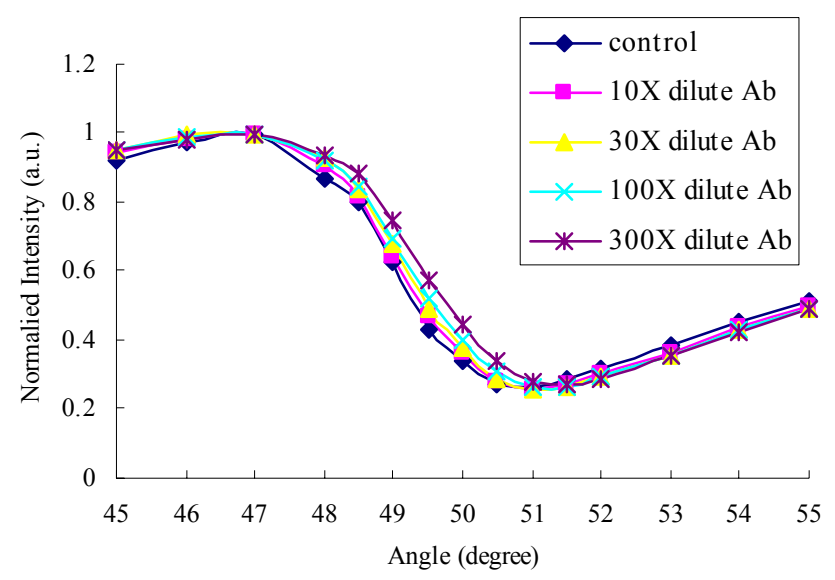

Fig. 4 Resonance angle curves analysis of antigen- antibody interaction

for W38

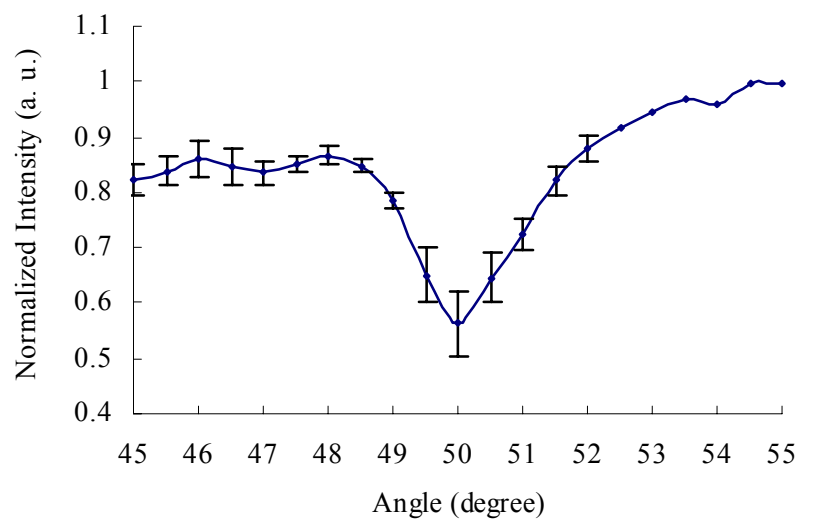

Fig. 5 Resonance angle analysis of control experiment $(n=4$ for each data points) for W06.

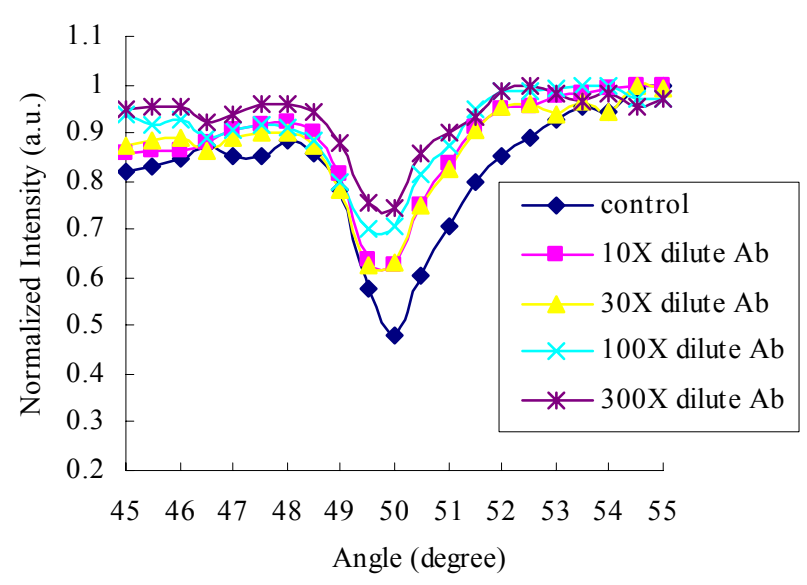

Fig. 6 Resonance angle curves analysis of antigen-antibody interaction for W06

TABLE 1 Statistics Of IMAgE INTENSITy AT DIFFERENT ANGLES

\begin{tabular}{|c||c|c|c|c|c|}
\hline Angle & Control & $10 \mathrm{X}$ & $30 \mathrm{X}$ & $100 \mathrm{X}$ & $300 \mathrm{X}$ \\
\hline 48.5 & $0.8197 \pm 0.0145$ & 0.8160 & 0.8351 & 0.8478 & 0.8845 \\
\hline 49 & $0.6383 \pm 0.0112$ & 0.6420 & 0.6763 & 0.6974 & 0.7487 \\
\hline 49.5 & $0.4563 \pm 0.0186$ & 0.4644 & 0.4921 & 0.5211 & 0.5715 \\
\hline 50 & $0.3548 \pm 0.0145$ & 0.3631 & 0.3776 & 0.4021 & 0.4481 \\
\hline 50.5 & $0.2811 \pm 0.0090$ & 0.2818 & 0.2881 & 0.3058 & 0.3382 \\
\hline
\end{tabular}

TABle 2 Resonance Angle Shift AT Different CONCENTRATION OF TB ANTIGEN w38

\begin{tabular}{|c|c|c|}
\hline Dilution & Angle & Angle Shift \\
\hline $10 \mathrm{X}$ & 51.8699 & 0.00585 \\
\hline $30 \mathrm{X}$ & 51.9457 & 0.08165 \\
\hline $100 \mathrm{X}$ & 52.0063 & 0.14225 \\
\hline $300 \mathrm{X}$ & 52.1024 & 0.23835 \\
\hline
\end{tabular}


TABle 3 Resonance ANGLE SHIFt At DifFERENT CONCENTRATION OF TB ANTIGEN W06

\begin{tabular}{|c|c|c|}
\hline Dilution & Angle & Angle Shift \\
\hline $10 \mathrm{X}$ & 49.9346 & 0.19398 \\
\hline $30 \mathrm{X}$ & 49.8634 & 0.26518 \\
\hline $100 \mathrm{X}$ & 49.6905 & 0.43808 \\
\hline $300 \mathrm{X}$ & 49.9968 & 0.13178 \\
\hline
\end{tabular}

ACKNOWLEDGEMENT

The authors thank the financial support of National Science Council, Republic of China, Taiwan (NSC-92- 2323-E-002004) in this study.

\section{REFERENCE}

[1] http:// www.who.int/en/

[2] W.P. Blackstock and M.P. Weir, Proteomics: quantitative and physical mapping of cellular proteins TIBTECH, vol. 17, pp. 121-120, Mar 1, 1999.

[3] R.A. Williams and H.W. Blanch, Covalent immobilization of protein monolayers for biosensor applications Biosensors \& Bioelectronics, vol. 9, pp. 159-167, 1994.

H. Wang, J.D. Brennan, A. Gene, and U.J. Krull, Assembly of antibodies in lipid membranes for biosensor development Applied Biochemistry \& Biotechnology, vol. 53, pp. 163-181, May, 1995.

[5] http://www.gwcinstruments.com/ 